\title{
THE IMPACT OF MOUTHGUARDS USAGE ON AEROBIC CAPACITY OF ATHLETES
}

\author{
Katarzyna Mańka-Malara', Dominika Zelik-Święch' ', Anna Jagielska², Aleksandra Kozłowska², Magdalena Łuniewska³, \\ Anahit Lewandowska', Magdalena Rączkiewicz', Elżbieta Mierzwińska-Nastalska', Dominika Gawlak' \\ 'Department of Prosthodontics, Medical University of Warsaw, Poland \\ ${ }^{2}$ Department of Social Medicine and Public Health, Medical University of Warsaw, Poland \\ ${ }^{3}$ Laboratory of Language Neurobiology, Nencki Institute of Experimental Biology, Polish Academy of Science, Warsaw, Poland
}

\begin{abstract}
INTRODUCTION: The use of intraoral mouthguards is the basic method of preventing injuries of the stomatognathic system while practicing extreme, contact, team and recreational sports. However, the presence of a protective splint in the mouth, especially during exercise, when increased oxygen uptake is needed, may adversely affect the level of blood oxygenation. It is also necessary to compare different types of splint as they differ in retention, size and comfort of usage.

Овјестіves: The aim of the study was to evaluate the effects of different intraoral mouthguard types for the cardiorespiratory capacity of athletes.

MATERIAL AND METHODS: Thirty athletes aged 20-37, testing a total of 120 intraoral mouthguards of different types two custom-made mouthguards prepared and two "boil and bite" splints adapted - took part in the study, in which cardiorespiratory capacity was compared using CRF, IF, METs and Watt indicators, based on tests conducted on the Fitmate device correlated with a stationary exercise bike.

RESULTS: The analysis of variance showed no differences between the compared parameters regardless of the tested mouthguard. The use of intraoral mouthguards during exercise does not affect the cardiorespiratory endurance of athletes.

ConcLusions: Mouthguards users, trainers and doctors should be informed about the lack of a negative impact of its usage during training and competition on cardio-respiratory endurance.
\end{abstract}

KEY WORDS: mouthguards, aerobic capacity, occlusal splints.

J Stoma 2019; 72, 4: 167-171

DOI: https://doi.org/10.5114/jos.2019.91234

\section{INTRODUCTION}

Breathing is one of the most important vital functions of the body, which is to remove carbon dioxide and oxygen supply. All cells contain mitochondria and are capable of producing high-energy bonds of adenosine triphosphate (ATP) in the process of oxidative phos- phorylation. Intracellular aerobic respiration consists of several consecutive biochemical processes: the tricarboxylic acid cycle, respiratory chain, transfer of electrons to molecular oxygen to form water and the construction of ATP binding, the final process that occurs in the lung gas exchange. Respiration, between the atmosphere and alveolar air of the lungs, takes place thanks to integrated

\section{JOURNAL OF} STOMATOLOGY CZASOPISMO STOMATOLOGICZNE

AdDRESS FOR CORRESPONDENCE: Katarzyna Mańka-Malara, Department of Prosthodontics, Medical University of Warsaw, 59 Nowogrodzka St., 02-006 Warsaw, Poland, e-mail: kmankamalara@gmail.com 
function of respiration and blood circulation. The basic value describing the amount of air entering the lungs is tidal volume $(\mathrm{Vt})$ and minute ventilation (the volume of air inhaled or exhaled in a minute). While resting, these values depend on age, sex, weight and respiratory rate. During exercise as the oxygen demand of working muscles increases the minute ventilation rises proportionally, reaching the value of maximum lung ventilation ( $\left.\mathrm{VO}_{2} \max \right)$ [1-4]. This parameter, also known as an indicator of cardiorespiratory fitness, is often used to compare the progression of exercise capacity of athletes and evaluate the impact of extrinsic factors. One of them is the use of mouthguards [5].

Nowadays, mouthguards are used more often when practicing sports with a risk of damage to the structures of the oral cavity [6-8]. Thanks to their structure, these viscoelastic polymer materials have the ability to reduce the force of injury by converting impact energy into heat or changing the shape of the chains [9-13]. Currently available mouthguards are the "boil and bite" type and custom-made ones. These types differ in retention, size, durability, comfort and material used. In the past also one-size stock-type splints were used. Custom-made intraoral guards provide sufficiently high comfort of usage, determined mostly by excellent retention and stabilization, while the commonly used "boil and bite" guards are often characterized by insufficient retention and less favorable mechanical properties. The presence in the mouth during sports of any of them could have negative effects on the circulatory-respiratory endurance of the athlete and reduce his or her performance [14-16].

\section{OBJECTIVES}

The aim of the study was to evaluate the effects of the presence of a mouthguard in the oral cavity on the cardiorespiratory capacity of the athlete.

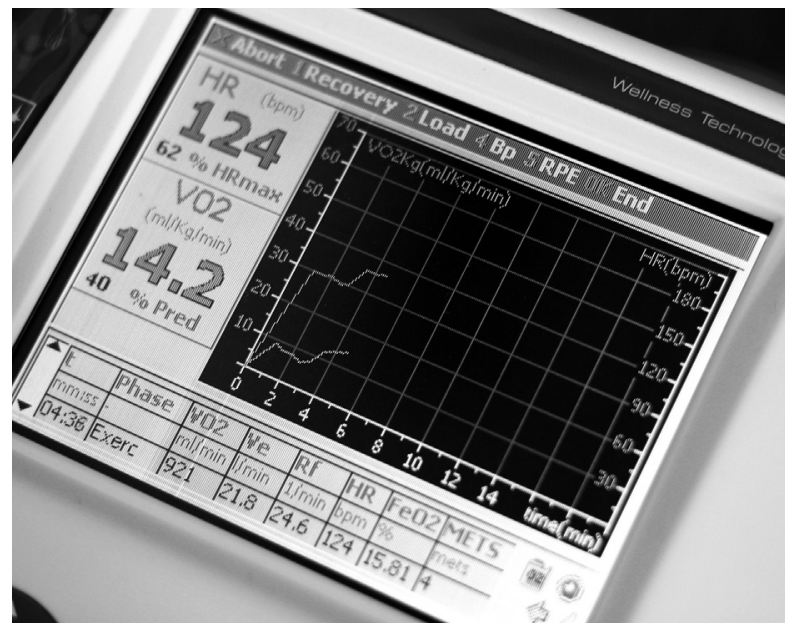

FIGURE 1. Fitmate appliance used to check the cardiorespiratory endurance

\section{MATERIAL AND METHODS}

The study involved 30 athletes, training professionally in disciplines involving regular application of mouthguards - American football and martial arts. Sixteen women and 14 men, aged 20-37 years, were testing a total of 120 intraoral mouthguards. All persons gave their informed verbal consent prior to their inclusion in the study. The research was conducted in accordance with the ethical standards laid down in the 1964 Declaration of Helsinki and its later amendments. The study presented was accepted by the Bioethics Commission of the Medical University of Warsaw - number of consent: $\mathrm{KB} / 221 / 2018$. The exclusion criteria included health contraindications to endurance training, cardiovascular diseases, respiratory disorders, organ and systemic diseases, disorders of the stomatognathic system, pain in the area of the temporomandibular joint, dental diseases or abnormalities. All athletes had previously used standard "boil and bite" type mouthguards. For each participant two custom-made mouthguards were prepared and two "boil and bite" splints were adapted. Custom splints were made using two techniques and materials:

- flasking - the Impak material (Vernon - Benshoff Comp., Albany, NY, USA) was used in a proportion of powder to liquid of $1.3: 1$;

- thermal injection - the Corflex Orthodontic materi-

al (Pressing Dental, Falciano, San Marino).

They were formed as recommended by the literature, with dimensions of 3-4 $\mathrm{mm}$ on the labial surface, $2 \mathrm{~mm}$ on the occlusal surface. "Boil and bite" mouthguards were also of two types - Porida (Combat Gear, Warsaw, Poland) and Shock Doctor Gel Max Strapless (Shock Doctor, Inc., Minnetonka, MN, USA). These splints were prepared by the athletes under the supervision of a dentist according the guidelines given by the manufacturer. Both custom-made and "boil and bite" mouthguards were used during training for a few weeks before cardio-respiratory capacity testing, in order to eliminate possible pain resulting from excessive pressure on the mucosa or other problems with guard usage. In the week before and during the test the study participants maintained a uniform, balanced diet arranged for the study to eliminate the impact of this factor.

The cardiorespiratory endurance of each athlete with or without an intraoral mouthguard was compared by a Fitmate (Cosmed, USA) (Figure 1) correlated with an exercise bike (Premium 8i, Daum Electronic, Fürth, Germany). Exercise capacity was assessed on an ergometer, with maximum oxygen uptake expressed in $\mathrm{ml} /$ $\mathrm{kg} / \mathrm{min}$ in a submaximal test (test protocol $20 \mathrm{~W} / \mathrm{min}$ ). The study of a single participant lasted for 5 days (consecutive days of the week). Every day, tests were performed without a mouthguard and then again after 30 minutes of rest, the test with the protector in the mouth. The study design is shown in Table 1. 
Measures were made of:

- cardiorespiratory fitness $(\mathrm{CRF})-\mathrm{VO}_{2}$ max expressed in $\mathrm{ml} / \mathrm{kg} / \mathrm{min}$,

- fitness index (FI),

- energy expenditure (METs - metabolic equivalent evaluating the intensity; 1 METs $\mathrm{O}_{2}$ consumption by a person weighing $70 \mathrm{~kg}$ while sitting at rest, $\mathrm{O}_{2}=3.5 \mathrm{ml} / \mathrm{kg} \times \mathrm{min}$ ),

- Watt - power unit.

During statistical analysis, the measurements were averaged from all control samples. Next, an analysis of variance (ANOVA) with repeated measures was conducted in order to investigate the difference in measurements (CRF, FI, METS and Watts) between the five conditions - types of mouthguards: 1) Shock Doctor, 2) Porida, 3) Corflex, 4) Impak, and 5) average control measurements.

\section{RESULTS}

The average value of CRF in the presence of a mouthguard made of Impak material was $47.94 \mathrm{ml} / \mathrm{kg} / \mathrm{min}$, while for Corflex material it was 47.80 , and values for "boil and bite" Shock Doctor and Porida protectors were 46.70 and 46.92, respectively. The FI reached during the test of Impak materials splints was 81.30 , while for Corflex material it was 81.57 , for Shock Doctor 80.13 and for Porida 79.97. Energy expenditure (METs) which the athletes reached during the test pad of Impak material averaged 13.69, while the value for Corflex material was 13.65, and values for standard Shock Doctor and Porida were 13.34 and 13.40, respectively. The parameter specifying the power achieved (Watt) showed the average level for the pad of Impak material to be 277.33, while for Corflex it was 277.0, and for the standard Shock Doctor and Porida it was 270.0 and 270.83, respectively. Average measurement values and their standard deviations for each of the pads and the averaged control measurements are presented in Table 2.

The analysis of variance showed no differences between groups for any of the measurements regardless of the mouthguard type (CRF: $F(4,116)=1.63, p=0.17$; FI: $F(4,116)=1.15, p=0.34$; METs: $F(4,116)=1.62$, $p=0.18$; Watt: $F(4,116)=1.34, p=0.26)$.

\section{DISCUSSION}

The achievement of high scores by the athletes largely depended on their cardiorespiratory predispositions.

TABLE 1. Design of the study of cardio-respiratory capabilities of the athletes

\begin{tabular}{|l|c|c|c|}
\hline Day of test & Control trial & Break & Mouthguard \\
\hline Monday & 1 & $30 \mathrm{~min}$ & Shock Doctor \\
\hline Tuesday & 2 & $30 \mathrm{~min}$ & Porida \\
\hline Wednesday & 3 & $30 \mathrm{~min}$ & Corflex \\
\hline Thursday & 4 & $30 \mathrm{~min}$ & Impak \\
\hline Friday & 5 & $30 \mathrm{~min}$ & Without - double control trial \\
\hline
\end{tabular}

TABLE 2. Average values of measurements (M) and standard deviations (SD) for evaluated parameters

\begin{tabular}{|c|c|c|c|c|c|}
\hline Parameter & Impak & Corflex & Shock & Porida & Control* \\
\hline \multicolumn{6}{|l|}{ CRF } \\
\hline M & 47.94 & 47.80 & 46.70 & 46.92 & 48.02 \\
\hline SD & 10.13 & 11.21 & 9.74 & 10.88 & 10.09 \\
\hline \multicolumn{6}{|l|}{$\mathrm{FI}$} \\
\hline M & 81.30 & 81.57 & 80.13 & 79.97 & 81.74 \\
\hline SD & 22.80 & 22.96 & 21.06 & 22.56 & 21.32 \\
\hline \multicolumn{6}{|l|}{ METS } \\
\hline M & 13.69 & 13.65 & 13.34 & 13.40 & 13.72 \\
\hline SD & 2.89 & 3.20 & 2.78 & 3.11 & 2.88 \\
\hline \multicolumn{6}{|l|}{ Watt } \\
\hline M & 277.33 & 277.00 & 270.00 & 270.83 & 278.67 \\
\hline SD & 81.17 & 88.15 & 79.04 & 82.98 & 81.94 \\
\hline
\end{tabular}

${ }^{*}$ Control = average results of the six control measurements

CRF - cardiorespiratory fitness, FI - fitness index, METS - metabolic equivalent evaluating the intensity 
Sports have a beneficial effect on physical strength, improve the function of the heart, lungs, and vascular system, and prevent metabolic diseases, such as diabetes and obesity. However, the practice of sport often brings complications or traumatic injuries [16-18]. Especially painful are injuries of the head and mouth, which athletes can minimize by using intraoral mouthguards. Despite this, there is a concern that the presence of a foreign body in the oral cavity, which a mouthguard undoubtedly represents, can restrict the flow of oxygen to the lungs, and thus decrease lung function and the athletes' performance $[10,19-22]$. In this study, no adverse effect of mouthguard application on athletes' cardiorespiratory endurance was discovered. Similar results are also presented in papers by other authors $[5,23,24]$.

In most of the cited publications, the authors investigated the influence of protectors on $\mathrm{VO}_{2}$ max. Maximum oxygen demand reported by Heller et al. [16] was $54 \mathrm{ml} / \mathrm{kg} \times \mathrm{min}$ for men and $41 \mathrm{ml} / \mathrm{kg} \times \mathrm{min}$ for women. Thompson and Vinueza [25] obtained an average score of $44 \mathrm{ml} / \mathrm{min} \times \mathrm{kg}$, while Drobnic et al. [10] obtained a result of $57-63 \mathrm{ml} / \mathrm{min} \times \mathrm{kg}$, and Keçeci et al. [17] obtained a result of $43.6 \mathrm{ml} / \mathrm{kg} \times \mathrm{min}$ (women) and 60 $\mathrm{ml} / \mathrm{kg} \mathrm{x} \mathrm{min} \mathrm{(men).} \mathrm{In} \mathrm{the} \mathrm{current} \mathrm{study,} \mathrm{we} \mathrm{compared}$ the CRF, which is synonymous with $\mathrm{VO}_{2}$ max, while using mouthguards made of Impak and Corflex materials, as well as Porida and Shock Doctor intraoral guards. Average results obtained for the different types of protectors respectively were $47.94,47.8,46.92$, and $46.7 \mathrm{ml} / \mathrm{min} \times \mathrm{kg}$, while for the control group the result was $48.02 \mathrm{ml} / \mathrm{min} \times \mathrm{kg}$. The results do not differ from those previously cited. In addition, in order to widen the spectrum of the study, other parameters were compared and physical efficiency was evaluated using METs, FI, and Watt as indicators. With regard to these parameters as well, no statistically significant differences were obtained when tests with different mouthguards types in the mouth were conducted and compared to those without protectors. What is noteworthy is the fact that slightly lower values of the studied parameters were recorded while standard Porida and Shock Doctor mouthguards were used, but due to the low sample number they are not statistically significant and may be only a matter of chance.

In previous studies which assessed the effect of the use of mouthguards on the physical performance of athletes, generally tests using a 20-meter run were carried out in accordance with the scheme proposed by Lager and Lambert [19]. Duddy et al. [12] also proposed interesting tests. Their study included two ergometer tests with different loads, giving the result in Watts, as well as a run. Eighteen 18 athletes were divided into 3 groups dependent on the type of mouthguard used, either standard or individual, while the control group was unprotected. Statistically, worse exercise capacity was observed when using a standard mouthguard during both phase 3 of the maximal load and in the 1-minute test.
Cetin et al. [1] compared the impact of protectors on athletes' endurance during a 20-minute sprint, jump, test of handgrip and back strength, and isometric leg exercises and found no statistically significant differences. However, the maximum and average power in the anaerobic Wingate test and hamstring isokinetic peak torque increased significantly when individual mouthguards were used. According to the authors of this paper, the authoritative endurance test may also be the ride on a stationary bike as the results do not differ from those previously published.

The advantage of the present study is the methodology of its implementation. In order to avoid any impact on the results of natural differences between participants in terms of gender, age, BMI, diet, hydration, fitness level, or emotional state, a significant number of test runs were conducted (6 for each athlete) without mouthguards in the mouth. Additionally, the study of the athlete lasted five days, which eliminated the possible influence of environmental factors, and the participants followed the uniform recommended diet. Other authors usually conducted two trials with a gap of one week or 48-week-hours [4, 12, 17].

Another beneficial aspect of the present study is the experience of the athletes in training with the protective splint in the oral cavity. This reduced the impact of the lack of adaptation to the presence of a foreign body in the mouth for the level of air intake. Keçeci et al. [17] and Duddy et al. [12] conducted tests among athletes who previously had not used any additional protection while training, which could have had an impact on the level of the neuro-muscular control of the stomatognathic system to an additional element in the oral cavity.

\section{CONCLUSIONS}

Mouthguards users, trainers and doctors should be informed about the lack of a negative impact of its usage during training and competition on cardio-respiratory endurance. They can be successfully used in all sport disciplines, according to recommendations, regardless of the required level of fitness endurance.

\section{CONFLICT OF INTEREST}

The authors declare no potential conflicts of interest with respect to the research, authorship, and/or publication of this article.

\section{References}

1. Cetin C, Kececi AD, Erdogan A, Baydar ML. Influence of custom-made mouth guards on strength, speed and anaerobic performance of taekwondo athletes. Dent Traumatol 2009; 25: 272 276.

2. Çetinbas T, Sönmez H. Mouthguard utilization rates during sport activities in Ankara, Turkey. Dent Traumatol 2006; 22: 127-132. 
3. Cohenca N, Roges RA, Roges R. The incidence and severity of dental trauma in intercollegiate athletes. J Am Dent Assoc 2007; 138: $1121-1126$

4. Collares K, Correa MB, Mohnsam da Silva IC, Hallal PC, Demarco FF. Effect of wearing mouthguards on the physical performance of soccer and futsal players: a randomized cross-over study. Dent Traumatol 2014; 30: 55-59.

5. Cooke CB. Maximal oxygen uptake, economy and efficiency. In: Eston R, Reilly T (eds.). Kinanthropometry and exercise physiology laboratory manual. Vol. 2: Exercise physiology. $2^{\text {nd }}$ ed. London: Routledge; 2003, p. 161-191.

6. Cornwell H, Messer LB, Speed H. Use of mouthguards by basketball players in Victoria, Australia. Dent Traumatol 2003; 19: 193-203.

7. Correa MB, Knabach CB, Collares K, Hallal PC, Demarco FF. Video analysis of craniofacial soccer incidents: a prospective study. J Sci Med Sport 2012; 15: 14-18.

8. Correa MB, Schuch HS, Collares K, Torriani DD, Hallal PC, Demarco FF. Survey on the occurrence of dental trauma and preventive strategies among Brazilian professional soccer players. J Appl Oral Sci 2010; 18: 572-563.

9. Del Rossi G, Leyte-Vidal MA. Fabricating a better mouthguard. Part I: factors influencing mouthguard thinning. Dent Traumatol 2007; 23: 149-154.

10. Drobnic F, Nunez M, Riera, J. Profil de condicion fisica del equipo nacional de Taekwondo. $8^{\text {th }}$ FIMS European Sports Medicine Congress, Granada, Spain, October 1995.

11. Duarte-Pereira DMV, Rey-Santamaria M, Javierre-Garces C, Barnaby-Cairo J, Paredes-Garcia J, Valmeseda-Castellon S, et al Wearability and physiological effects of custom-fitted vs selfadapted mouthguards. Dent Traumatol 2008; 24: 439-442.

12. Duddy FA, Weissman J, Lee RA Sr, Paranipe A, Johnson JD, Cohenca N. Influence of different types of mouthguards on strength and performance of collegiate athletes: a controlled-randomized trial. Dent Traumatol 2012; 28: 263-267.

13. Eroglu E, Diljin KA, Leutfi BM. Elite tae kwon do athletes satisfaction with custom-made mouthguards. Dent Traumatol 2006; 22 193-197.

14. Gawlak D, Mierzwińska-Nastalska E, Mańka-Malara K, Kamiński T. Comparison of usability properties of custom-made and standard self-adapted mouthguards. Dent Traumatol 2014; 30: 306-311.

15. Glendor U. Aetiology and risk factors related to traumatic dental injuries - a review of the literature. Dent Traumatol 2009; 25: 19-31.

16. Heller J, Peric T, Dlouha R, Kohlikova E, Melichna J, Novakova H. Physiological profiles of male and female taekwon-do (ITF) black belts. J Sports Sci 1998, 16: 243-249.

17. Keçeci AD, Cetin C, Eroglu E, Baydar ML. Do custom-made mouth guards have negative effects on aerobic performance capacity of athletes? Dent Traumatol 2005; 2: 276-280.

18. Kerr IL. Mouth guards for the prevention of injuries in contact sports. Sports Med 1986; 3: 415-427.

19. Léger LA, Lambert J. A maximal multistage $20 \mathrm{~m}$ shuttle run test to predict VO2 max. Eur J Appl Phys 1982; 49: 1-12.

20. Léger LA, Mercier D, Gadoury C, Lambert J. The multistage 20 metre shuttle run test for aerobic fitness. J Sport Sci 1988; 6: 93-101.

21. Lieger O, von Arx T. Orofacial/cerebral injuries and the use of mouthguards by professional athletes in Switzerland. Dent Traumatol 2006; 22: 1-6.

22. Newsome PRH, Tran DC, Cooke MS. The role of the mouthguard in the prevention of sports-related dental injuries: a review. Int J Paed Denti 2001; 11: 396-404.

23. Perunski S, Lang B, Pohl Y, Filippi A. Level of information concerning dental injuries and their prevention in Swiss basketball - a survey among players and coaches. Dent Traumatol 2005; 21 195-200.

24. Pribble JM, Maio RF, Freed GL. Parental perceptions regarding mandatory mouthguard use in competitive youth soccer. Inj Prev 2004; 10: 159-162.

25. Thompson WR, Vinueza C. Physiologic profile of Tae Kwon Do black belts. Sports Med Train Rehab 1991; 3: 49-53. 